ASEE's 123rd Annual • Conference \& Exposition • New Orleans, LA • June 26-29, 2016

\title{
Developing Design Skills in an Introductory Mechanics of Solids Course
}

Dr. Edward M. Segal, Hofstra University

Dr. Edward M. Segal is an Assistant Professor in the Engineering Department at Hofstra University.

Prof. Sigrid Adriaenssens, Princeton University 


\title{
Developing Design Skills in an Introductory Mechanics of Solids Course
}

\begin{abstract}
One challenge architectural and civil engineering departments face while preparing their students for the global workforce is including design projects that tackle real world problems, in an already full academic curriculum. This paper describes an approach to helping students develop structural engineering design skills in an introductory level mechanics of solids class. This approach includes three components: (i) a process book, (ii) a design workshop, and (iii) a postdesign workshop critique. The specific design skills that students learn and practice include problem scoping, brainstorming, sketching, generating and evaluating alternative schemes, and critique. Additionally, through this project, students contextualize their understanding of the fundamental principles of solid mechanics. The merit of this project is that students can successfully learn design skills in an existing introductory engineering course.
\end{abstract}

\section{Introduction}

Engineering design projects that focus on real world problems can help prepare students for the challenges that they will face later in research settings and industry. In some architectural and/or civil engineering curricula, students are exposed to design in first-year and/or senior capstone courses. In an existing academic curriculum that lacks first-year and/or senior capstone courses it may not be feasible to add new courses that are entirely focused on design. As an alternative to standalone design courses, design components can be integrated into other courses that are already part of the curriculum. Bucciarelli ${ }^{1}$, in a review of a workshop held by the Engineering Coalition of Schools for Excellence in Education and Leadership (ECSEL), describes a set of design projects that were incorporated into courses such as statics and mechanics of solids by participants in the ECSEL. These projects range from exercises derived from textbook problems to the design of steel and/or concrete bridges, but Bucciarelli ${ }^{1}$ indicates that the link between these projects is their open-ended nature.

At Princeton University there is an upper level engineering course focused on the design of buildings, but no required first-year course devoted exclusively to engineering design. To provide students with opportunities to develop design skills early in their university education without introducing a new course, a set of design components was incorporated into an existing introductory mechanics of solids course. This version of the course was offered twice (Fall 2012 and Fall 2013) and was taken by forty-seven students.

The specific design components that were added to the existing mechanics of solids course at Princeton University were: (i) a process book (i.e., sketch book with an emphasis on the process of design), (ii) a design workshop, and (iii) a post-design workshop critique. These components were spread throughout the semester and integrated with the solid mechanics material to create an extended and open-ended design project. This project was largely focused on understanding 
and redesigning the Sabrina Footbridge (Worcester, England, 1992), a cable-stayed bridge engineered by SKM Anthony Hunts (Figure 1). The Sabrina Footbridge was selected specifically because it is a statically determinate structure. Hence the bridge required few simplifying assumptions for the students to understand its structural behavior and allowed them to explore the influence of different design changes such as increasing the number of cables, using a different cable arrangement, inclining the tower, and altering the tower configuration.

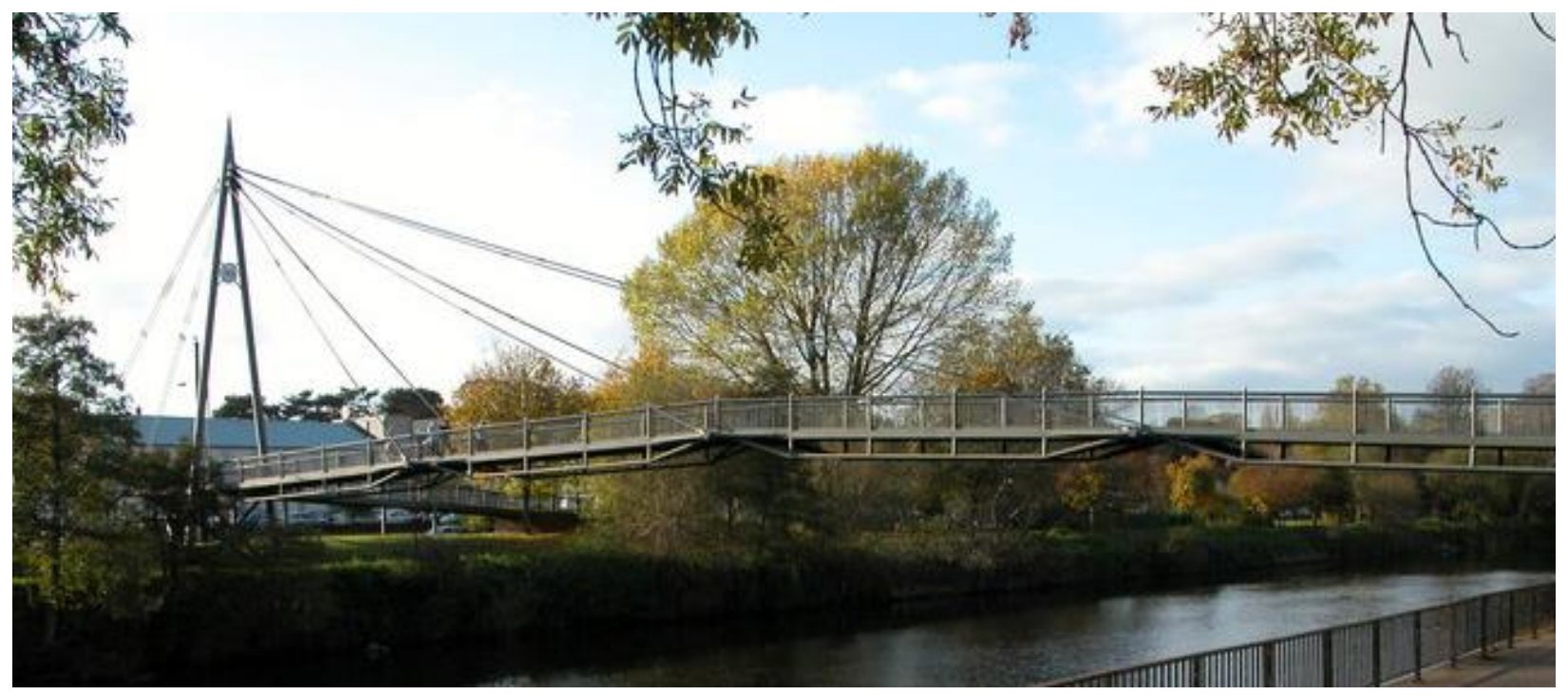

Figure 1. Sabrina Footbridge in perspective. Photograph courtesy of Philip Halling ${ }^{2}$.

The course learning objectives associated with this project combined three forms of language: words, graphics, and mathematics ${ }^{3}$ and focused on emphasizing critical design skills such as problem scoping ${ }^{4}$, brainstorming, sketching ${ }^{5}$, generating and evaluating design alternatives, and critique $^{6}$. The specific learning objectives were:

1) The student will be able to describe objects verbally, graphically, and mathematically. Provided an object, the student will be able to put down on paper words, drawings, and equations that characterize the object's features.

2) The student will be able to scope a design problem. Provided a prompt, the student will be able to: (i) list the design constraints and goals and (ii) gather additional information and articulate assumptions not listed in the prompt, but required to achieve the design goals.

3) The student will be able to generate and evaluate design alternatives. Provided a prompt, the student will be able to: (i) hand sketch (rough drawings) multiple design schemes, (ii) compare how the different schemes impact cost, aesthetics, and the flow of forces through the structure, and (iii) select the scheme that most closely aligns with the design goals and refine that design.

4) The student will be able to receive and give design critiques. The student will be able to: (i) interpret and respond to critiques of his/her designs provided by instructors, outside critics, and 
peers through design revisions and written comments and (ii) write critiques of his/her own designs and those of others.

Students strove to meet these learning objectives by completing the three design components: (i) process book, (ii) design workshop, and (iii) post-design workshop critique. The remainder of this paper discusses these design components.

\section{Process book}

Students worked toward meeting learning objectives $1-3$ by practicing designing in their process books through six prescribed assignments ("design experiences"). Additionally, students explored their own interests and related them to the primary course content by creating a set of supplemental entries. The process of design was emphasized by distributing the process book submissions throughout the semester and encouraging students to reflect on and revise their work.

In the remainder of this section, the six prescribed Fall 2013 assignments are described. Additional information regarding the supplemental entries is also discussed.

\section{Design experience 1}

In design experience 1, students scoped a problem and brainstormed. They were given the cut sheet provided by SKM Anthony Hunts describing the Sabrina Footbridge and were asked to determine the design constraints, design goals, and additional information needed to completely define the goals and constraints (Figure 2). Then, the students described (in words, sketches, and equations) how a few of these design constraints and goals related to what they had learned in class about free body diagrams and equations of equilibrium.

\section{Design experience 2}

In design experience 2, students drew and labeled the bridge components that they observed in a set of Sabrina Footbridge photographs. The students had to slow down and closely examine all the components to draw the bridge accurately. A detailed perspective drawing of the bridge is presented in Figure 3. 


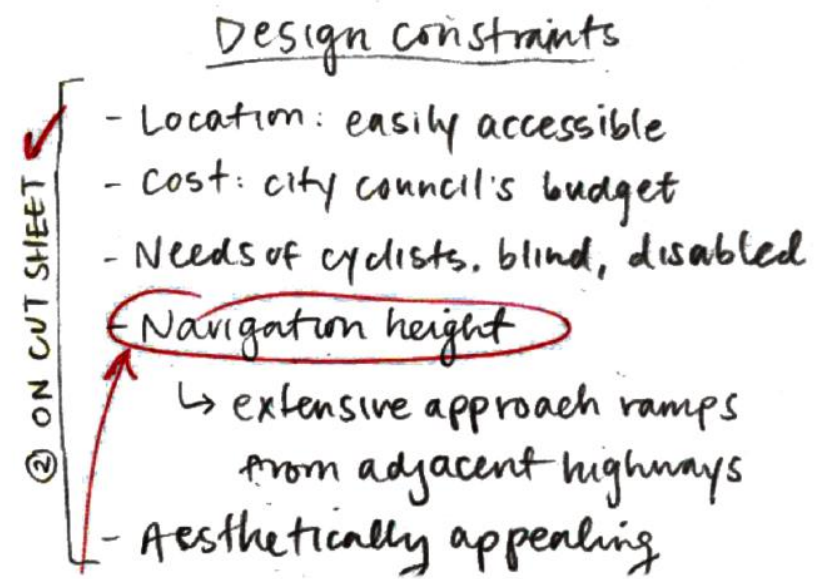
Design Goals
- Improve access to city centre for pedestrans a cyclists
- Reduce danger c existing highway bridge
- Easy use by cyclists * wheelchair users

Figure 2. List of design constraints and goals for the Sabrina Footbridge. Figure courtesy of Michelle Chang.

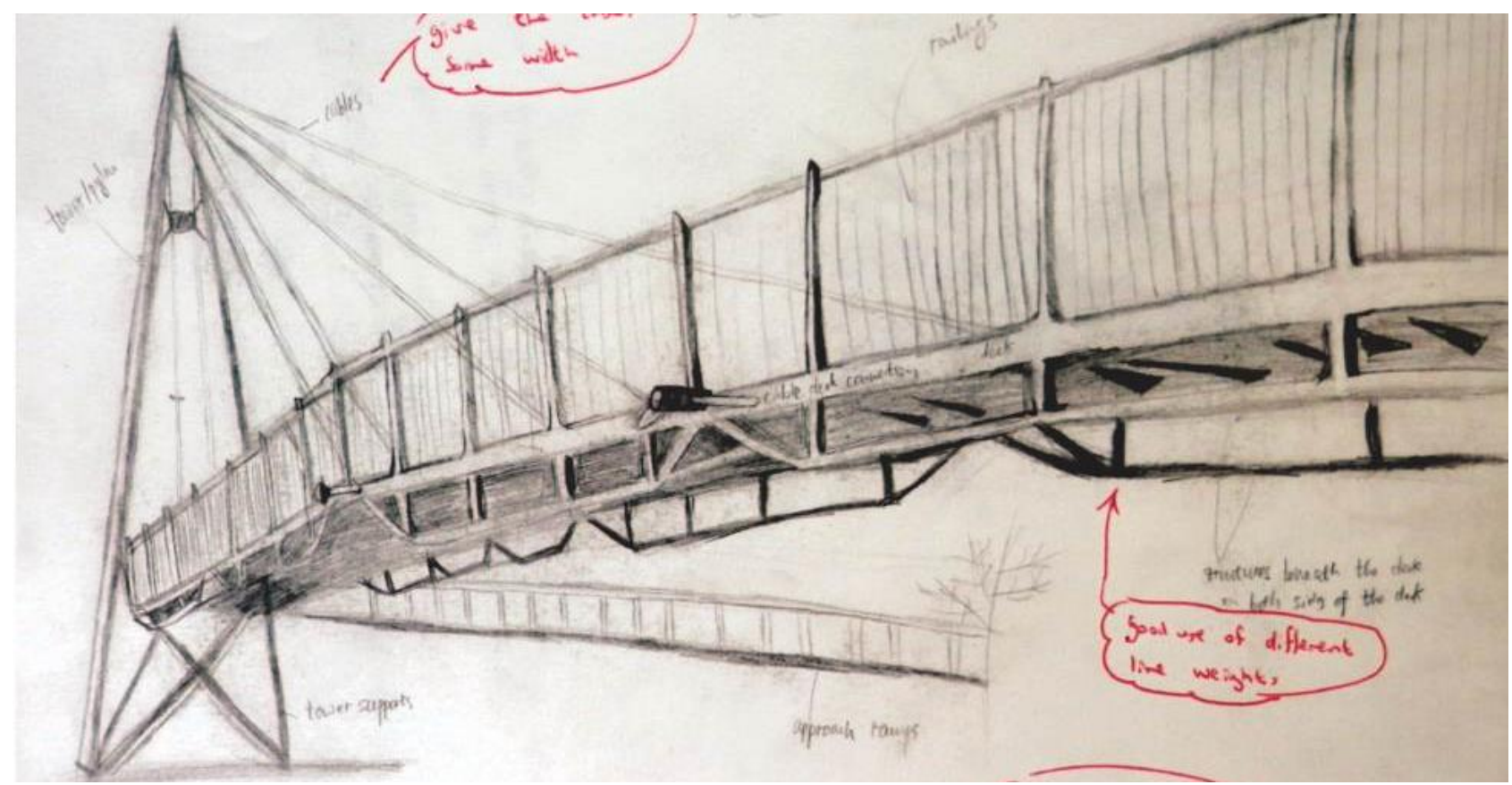

Figure 3. Drawing of the Sabrina Footbridge in perspective. Drawing courtesy of Lu Lu.

\section{Design experience 3}

In design experience 3, students sketched a set of existing bridges using a limited number of lines. To draw a reasonable representation of an entire bridge required students to think about the most important elements of the structure ${ }^{7}$. They learned how to generate an abstraction of a physical object that could then serve as the basis for generating a free body diagram. An abstraction of the Sabrina Footbridge is presented in Figure 4. 

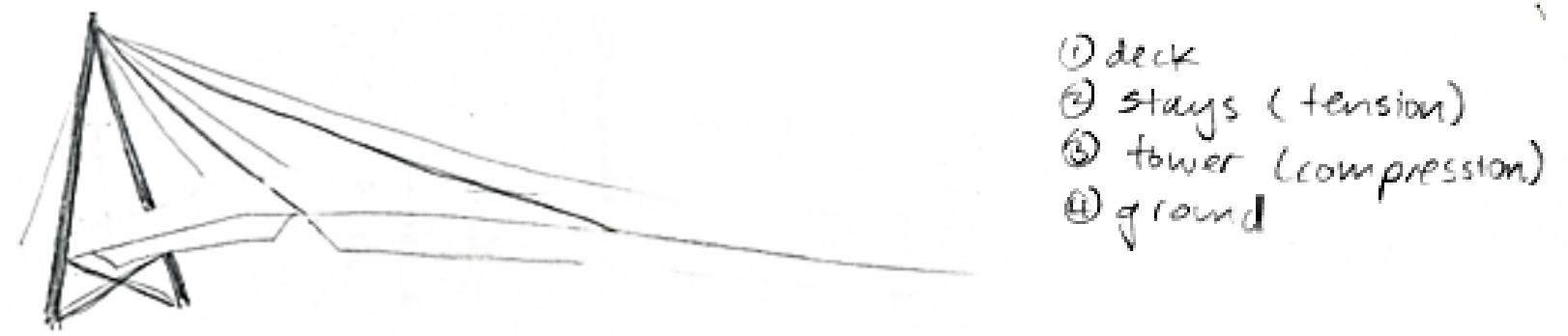

Figure 4. Drawing of the Sabrina Footbridge limited to approximately fifteen lines. Drawing courtesy of Demi L. Fang.

\section{Design experience 4}

In design experience 4, students generated different design alternatives for the Sabrina Footbridge and reflected on their design decisions. Students were prompted to make the following specific changes to the bridge: (1) increase the number of cables, (2) replace the fan cable arrangement with a harp cable arrangement, (3) incline the tower, and (4) replace the two member tower with a one member tower. Students considered each change in a different sketch (Figure 5). Billington and Nazmy's article, "History and Aesthetics of Cable-Stayed Bridges," was provided to students so that they could review a set of precedent bridges when generating their own designs.
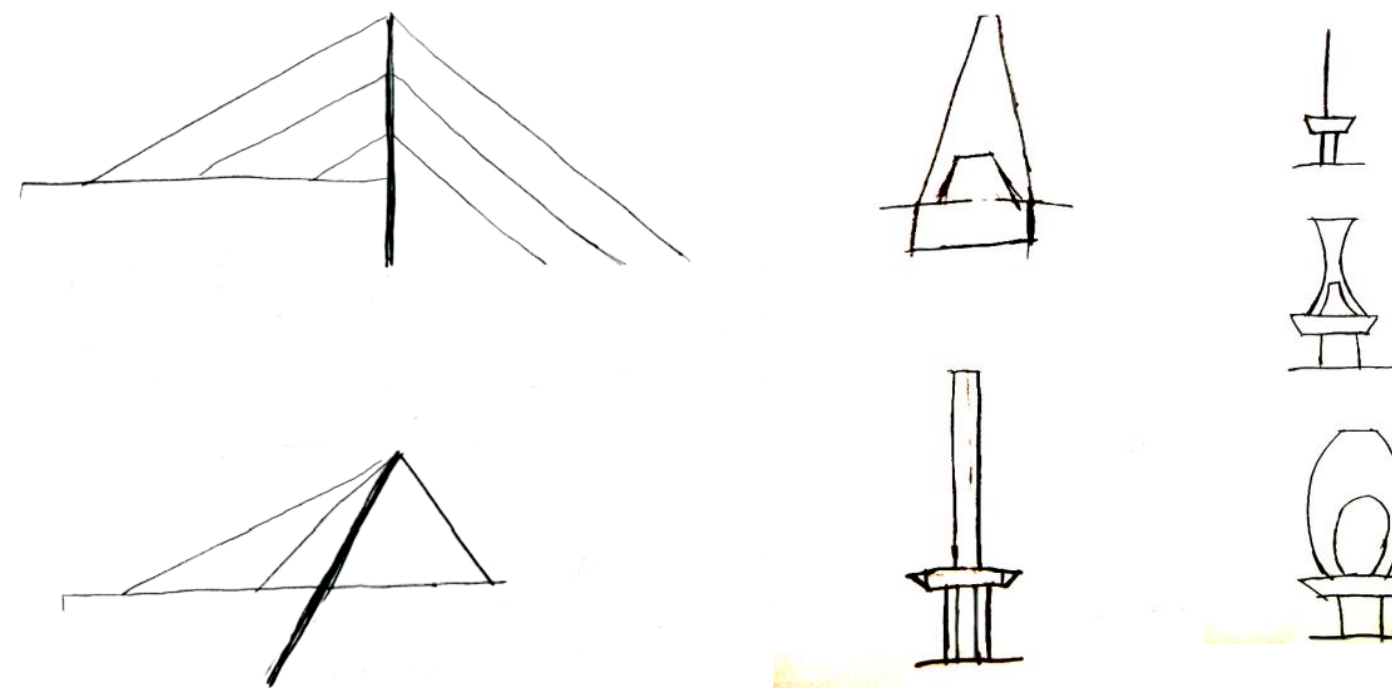

Figure 5. Drawings of design alternatives. On the left, drawings of a harp cable arrangement (top) and an inclined tower (bottom). Drawing courtesy of Demi L. Fang. On the right, a series of five single member tower designs. Drawings courtesy of $\mathrm{Lu} \mathrm{Lu}$.

\section{Design experience 5}

In design experience 5, students compared the alternative designs that they created in design experience 4 to the actual Sabrina Footbridge design. They considered how changes influenced the flow of forces through the structure by using interactive structural analysis tools like Active 
Statics $^{9}$ and eQUILIBRIUM ${ }^{10}$ (Figure 6). Additionally, students described how the changes could influence material and construction costs as well as aesthetics. In making these assessments they considered the impact of changes to geometry, cross-section, number of elements, required connections, etc. For the aesthetic evaluations, students used the criteria presented in Menn's article "Aesthetics in Bridge Design"11.
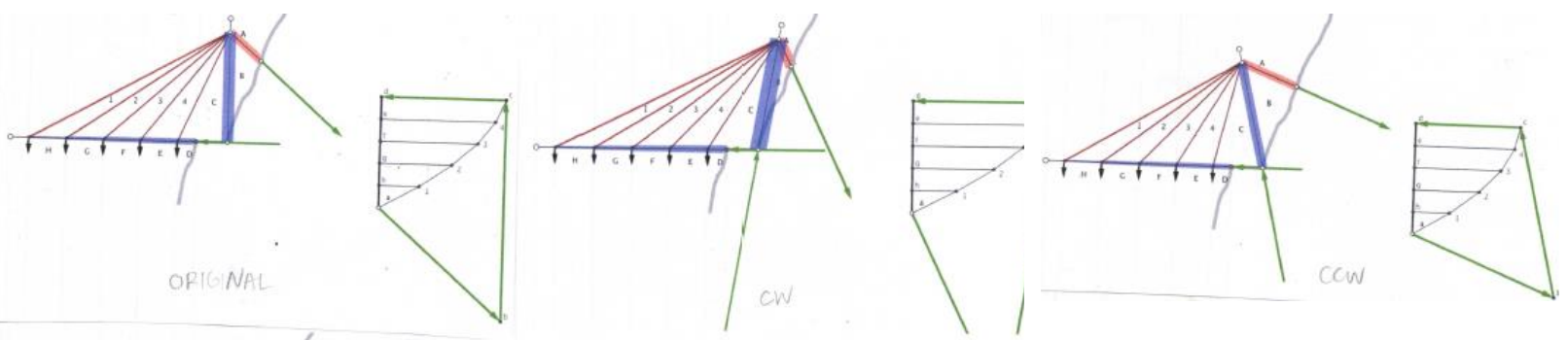

Figure 6. Schematics from eQUILIBRIUM demonstrating how inclining the tower in different directions influenced the flow of forces through the structure. Figures courtesy of Michelle Chang.

\section{Design experience 6}

In design experience 6, students created a "final" redesign of the Sabrina Footbridge by revising and/or refining their earlier design changes. First, the students sketched their bridges from multiple angles. Then, they outlined the steps needed to analyze the structure. In this outline, students included relevant equations from the primary course content as well as additional sketches as necessary. Finally, the students reflected on their designs by evaluating how well the designs aligned with the goals and constraints that they listed in design experience 1 and elaborating on their specific design decisions.

\section{Supplemental entries}

Supplemental entries complemented the six prescribed design experience assignments by allowing students to make connections between the primary course content and other structures of their choosing. Examples of entries included: an exploration of column cross-sections, a study of different wind-resisting systems in skyscrapers, and a series of sketches of bridges designed by Santiago Calatrava (Figure 7) and Schlaich Bergermann and Partner. 

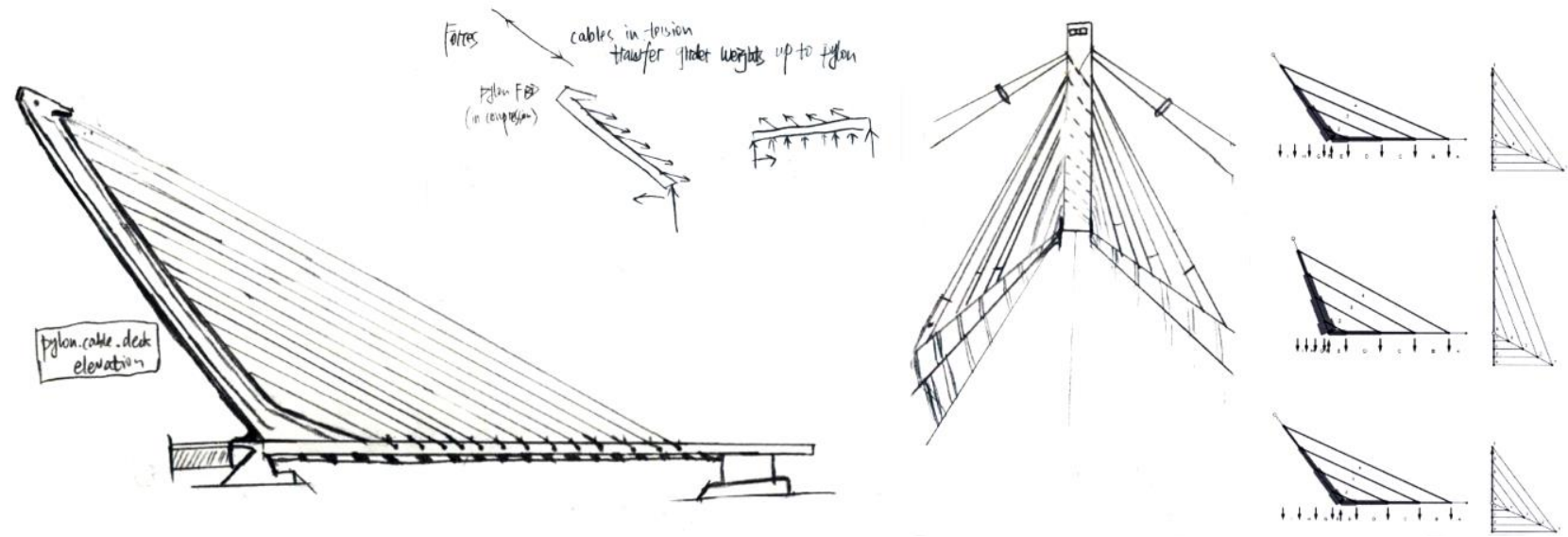

Figure 7. On the left and in the center, drawings of Santiago Calatrava's Alamillio Bridge. Inset, free body diagrams. On the right, schematics from eQUILIBRIUM demonstrating the influence of tower angle on the forces in a bridge with no back stays. Drawings courtesy of Lu Lu.

\section{Design workshop}

Students worked toward meeting learning objectives $1-4$ in an end-of-semester design workshop. The general prompt was to redesign the Sabrina Footbridge assuming the same design constraints and goals identified in the process book (design experience 1), but accounting for a span twice that of the original bridge ( $124 \mathrm{~m}$ versus $62 \mathrm{~m}$ ). Designs were no longer required to be of the cable-stayed from. In a set of group exercises, the students synthesized the skills that they practiced in their process books throughout the semester. Evolved designs created by different groups are presented in Figure 8.

These exercises were complemented by desk critiques and presentations by practicing engineers. The desk critiques gave the students opportunities to ask questions and receive feedback on their designs from the engineers. These interactions were intended to provide the students with greater perspective on how design decisions influence the flow of forces, construction, economy, aesthetics, etc. The presentations focused on each engineer's individual design process and included reflections and discussions on constraints, sketches, calculations, communication with owners and clients, construction (economy and techniques), and the successes and failures along the way.

\section{Post-design workshop critique}

Students worked toward meeting learning objective 4 by writing self and peer critiques of the evolved designs generated during the workshop. Each student wrote a critique of his/her group's design and one other group's design. Potential, but not required topics for the critiques included: how well the defined constraints and goals were met, clarity of concept in drawings and words, and structural feasibility. Critiques were required to include constructive comments and probing questions. The critiques were the final design component in the course, but they were intended to reinforce the idea that design is an ongoing process. 


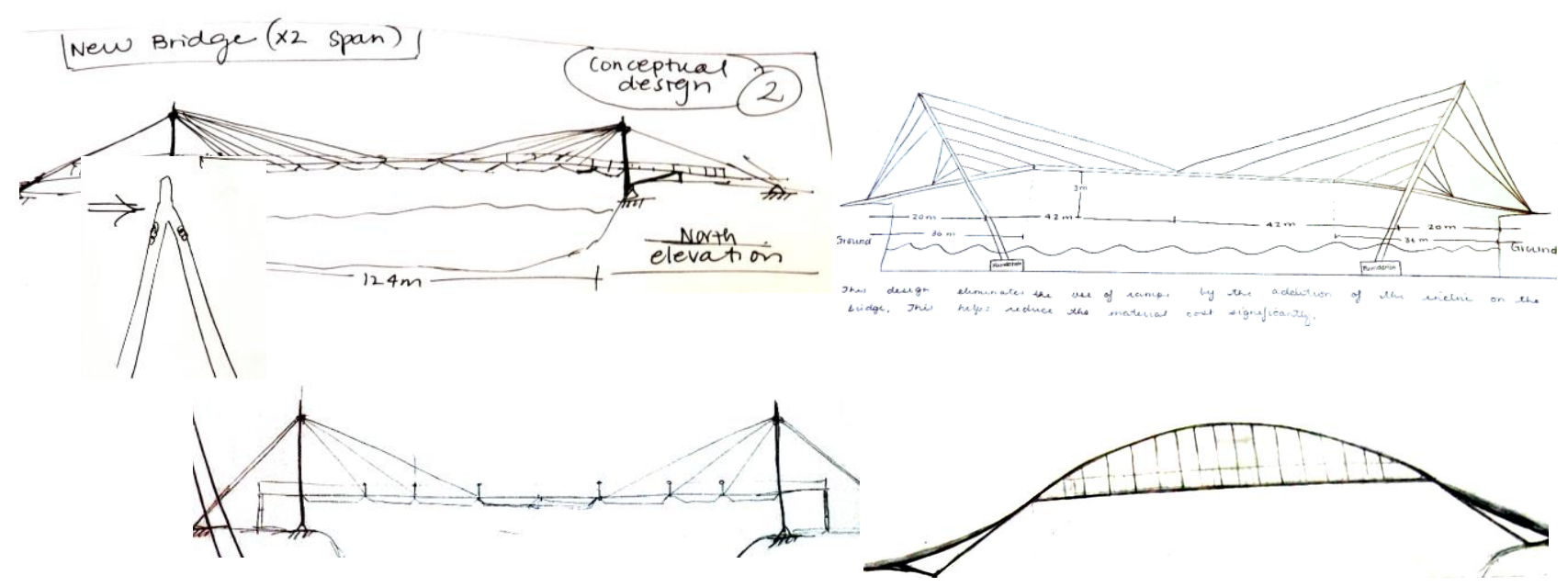

Figure 8. Drawings of evolved designs generated by different groups of students. The drawings on the top and bottom left are courtesy of Jamie Simpson, Shaun Stojak, and Ingrid Yen. The drawing on the top right is courtesy of Elizabeth McDonald and Kevin Tresselt. The drawing on the bottom right is courtesy of Pelin Asa and Kathryn Little.

\section{Conclusions}

This paper presented a semester-long structural engineering design project that was incorporated into an introductory mechanics of solids course. Through this project, students developed structural engineering design skills and contextualized their understanding of the fundamental principles of solid mechanics. The design skills that students practiced as part of this project included problem scoping, brainstorming, sketching, generating and evaluating design alternatives, and critique. Taken as a set, these skills required students to utilize three forms of language: words, graphics, and mathematics.

The anonymous end of semester survey included questions related to the impact of the project and its components. One student stated:

The design experience helped to unify the course and make the course more practical. It was integral to the course.

The design project was not viewed by the students as an add-on to the course, but rather as a crucial course component. Another student wrote:

I am more excited/motivated to pursue a career in engineering because this experience helped show the creative nature that accompanies all of the math that engineers have to do.

In the end of semester survey, students were asked to rate their level of motivation to pursue a career in engineering following this design project. Tabulated responses regarding the students' motivation are presented in Table 1. 
Table 1. Student responses to their level of motivation to pursue a career in engineering following this design project.

\begin{tabular}{lcc}
\hline Level of motivation & 2012 results & 2013 results \\
\hline More motivated & $50.0 \%$ & $60.7 \%$ \\
Same motivation & $37.5 \%$ & $32.1 \%$ \\
Less motivated & $0.0 \%$ & $0.0 \%$ \\
Response did not clearly fall into one of the categories above & $12.5 \%$ & $7.1 \%$ \\
\hline
\end{tabular}

The results in Table 1 indicate that the majority of students in both offerings of the course were more motivated to pursue a career in engineering in contrast to having the same or less motivation. In written comments, students acknowledged that there was more to learn, but they reflected positively on the practical and creative experience gained through this project and they are looking forward to continuing in engineering. Further assessment is required to determine the impact of this design project on the design skills demonstrated by students in design courses taken later in the academic curriculum and on the job. One method of assessment could be to survey the instructors of higher level courses and employers to compare the design proficiency of students that have and have not participated in this project.

The specific design components presented in this paper were developed to integrate into an existing course, rather than stand alone in a new course. Where existing curricula do not allow for the addition of new design courses, inclusion of similar components into typically required courses such as introductory mechanics of solids may be possible. These design components can provide students with exposure to practical problems and opportunities to develop critical skills early in their education that can help prepare them for the global workforce.

\section{Acknowledgements}

This work was supported by funding through the Princeton University Keller Center. The authors would like to thank their Fall 2012 and 2013 Mechanics of Solids students for participating in and providing feedback regarding this project. Additionally, the authors are grateful to Professor Landolf Rhode-Barbarigos (University of Miami, USA), Holger Schulze-Ehring (SGH, USA), Juan Sobrino (Pedelta, Canada), Michael Stein (sbp, USA), and Theodore P. Zoli (HNTB, USA) for joining the design workshops as speakers and/or critics. The authors also wish to thank Carol Porter (Princeton University, USA) for discussions related to this project and Kendall Schmidt (Princeton University, USA) for reviewing the manuscript and assisting with the figures.

\section{Bibliography}

1. Bucciarelli, L. L. (1998). Learning by Design - What Have We Learned. Paper presented at the ASEE Annual Conference, Seattle, WA. 
2. Halling P. The Sabrina Bridge Worcester - geograph.org.uk - 280039.jpg (c2006, accessed 2015, April 6. Website: http://commons.wikimedia.org/wiki/File:The_Sabrina_Bridge,_Worcester_-_geograph.org.uk__280039.jpg. Licensed under CC BY-SA 2.0 via Wikimedia.

3. Matteo, J. A. (2011). Preservation Engineering: Framing a New Curriculum. Preservation Education \& Research, 4, 93-106.

4. Atman, C. J., Adams, R. S., Cardella, M. E., Turns, J., Mosborg, S., and Saleem, J. (2007). Engineering Design Processes: A Comparison of Students and Expert Practitioners. Journal of Engineering Education, 96(4), 359-379.

5. Goldschmidt, G. (1994). On Visual Design Thinking: The Vis Kids of Architecture. Design Studies, 15(2), 158174.

6. Kuhn, S. (2001). Learning from the Architecture Studio: Implications for Project-Based Pedagogy. International Journal of Engineering Education, 17(4-5), 349-352.

7. Gauvreau, P. (2012). Design Education for the 21st Century. Festschrift Billington. E. M. Hines, S. G. Buonopane, and M. E. M. Garlock, International Network for Structural Art, p. 92-121.

8. Billington, D. P. and Nazmy A. (1990). History and Aesthetics of Cable-Stayed Bridges. Journal of Structural Engineering, 117(10), 3103-3134.

9. Greenwood, S. and Allen, E. Active Statics (c2003, accessed 2015, April 8). Website:

http://acg.media.mit.edu/people/simong/statics/data/

10. Block Research Group. eQUILIBRIUM: An Interactive, Graphic Statics-Based Learning Platform for Structural Design (c2009-2012, accessed 2015, April 6). Website: http://block.arch.ethz.ch/equilibrium/drawings

11. Menn, C. (1983). Aesthetics in Bridge Design. Journal of the International Association for Shell and Spatial Structures, 26-2(88), 53-62. 